

\title{
Emergence of teleradiology, PACS, and other radiology IT solutions in Acta Radiologica
}

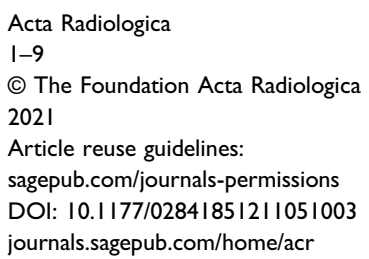

(S)AGE

\author{
GQ। Jarmo Reponen ${ }^{1,2}$ (D) and Jaakko Niinimäki' ${ }^{1,3}$
}

GQ2 Abstract

GQ4 For this historical review, we searched a database containing all the articles published in Acta Radiologica during its 100 GQ5 year history to find those on the use of information technology (IT) in radiology. After reading the full texts, we selected the presented articles according to major radiology IT domains such as teleradiology, picture archiving and communication systems, image processing, image analysis, and computer-aided diagnostics in order to describe the development as it appeared in the journal. Publications generally follow IT megatrends, but because the contents of Acta Radiologica are mainly clinically oriented, some technology achievements appear later than they do in journals discussing mainly imaging informatics topics.

\section{Keywords}

Teleradiology, PACS, computer-aided diagnostics, technical aspects

Date received: 8 June 202I; accepted: 17 September 202 I

\section{Introduction}

Radiology is a technically oriented field of medicine, and thus technical innovations have been eagerly presented in the literature. Radiologists have been in the vanguard of adopting computers and digital technology and this is reflected in the numerous reports published in past decades in scientific journals. In this historical review, we present how information technology (IT) has evolved in several topics as its ideas and studies have been published in Acta Radiologica. We performed a targeted search of a reference list containing titles of all the articles published in Acta Radiologica since 1921. We retrieved the articles from online literature databases on the basis of their title; whether they discussed on the use of IT for image transmission, display and archiving; or whether they described computerized image processing or image and data analysis or digital technology in radiology work practice. Articles containing only digital image acquisition technology were excluded from this study. After reading the full articles, their suitability for this review was agreed in a consensus panel consisting of the two authors of this paper. Finally, the articles were presented according to the main radiology IT domains and when relevant, the texts were linked to published parallel development elsewhere in the literature.

\section{Findings according to the domains}

\section{Teleradiology}

The idea of the tele-transmission of image data emerged already in 1924, when Radio News Magazine published a futuristic cover story anticipating future doctors attending to their patients via video calls (1). The first mention of teleradiology dates back to 1929 , when two dental photographs were transmitted by telegraph and the image quality was good enough to show filled root channels (2). Gershon-Cohen and Cooley used telephone lines and facsimile technology (3), demonstrating future solutions for low-cost teleradiology in rural areas. Finally, in the

\footnotetext{
'Research Unit of Medical Imaging, Physics and Technology, University of Oulu, Oulu, Finland

${ }^{2}$ Medical Research Center Oulu, Oulu University Hospital and University of Oulu, Oulu, Finland

${ }^{3}$ Department of Diagnostic Radiology, Oulu University Hospital, Oulu, Finland
}

\section{Corresponding author:}

Jarmo Reponen, Research Unit of Medical Imaging, Physics and Technology, University of Oulu, P.O. Box 5000, Oulu, FI-900I4, Finland. Email: jarmo.reponen@oulu.fi 
1950s, television (TV) technology was developed to a level that enabled its use in diagnostic consultations (4).

During the same period in the 1950s, Wallman and Wickbom (5) published an article in Acta Radiologica (hereafter Acta) describing the usage of röntgen-television technology in an operating room. This article was the first to describe TV technology in Acta-although it was not exactly teleradiology, many of its components could have been used for teleradiology: display and image capture were separated, an image memory was created, and radiologists could discuss the image with a surgeon. The article also used the term "electronic photography," which preceded digital imaging. However, image quality concerns also arose; the authors mentioned, for example, that only five levels of gray were distinguishable.

The applications of TV technology were discussed in various articles (6-8) and then in 1966 the first article on the usage of close-circuit TV technology in image transmission was published in Acta (9). The technology's capabilities had increased; the authors mentioned that the limiting factor for diagnosis was no longer line resolution but contrast separation ability.

As the beginning of a new era in teleradiology, in 1986, Nilsson et al. (10) published a baseline article in Acta, describing all the necessary components of teleradiology transmission over telephone lines and presenting the initial clinical experience. The images of 62 patients were digitized using a modest $256 \times 256$ matrix, but no loss of image quality or diagnostic information occurred in the computed tomography (CT) images. For conventional $\mathrm{X}$-rays, image quality deterioration was observed, although none of the cases were non-diagnostic. The authors believed that a few carefully selected images could be sufficient for adequate consultation.

The next step forward was in the mid-1990s, when several articles in Acta described digital teleradiology facilitated by computer workstations and information networks. In computer workstations, the largest image matrix sizes had increased significantly to $2048 \times 2048$ or $1024 \times$ 1024 , which were considered adequate for making diagnoses based on chest X-rays (11). Beyond this technology revolution, these articles discussed the clinical results and application areas of teleradiology. Comparison studies showed the limits and possibilities of teleradiology in comparison to film-based image interpretation, and further training of radiologists to work on the electronic workstation was called for (12). Improved telecommunication networks enabled teleangiology pilots either by the conventional videoconference technique or using a personal computer master-slave technique (13). At this time, two major changes were simultaneously taking place: image reading on computer terminals and the division of radiologic interpretation work between the imaging site and the reading site. In summary, by the end of the 1990s, all the important components of modern teleradiology had been discussed in
Acta: image scanners; digital connections; computer workstations; and high-resolution monitors. Evaluation studies included the assessment of diagnostic performance $(11,12)$.

In comparison to the situation elsewhere, the development of digital teleradiology was substantial in many of the Nordic countries towards the turn of millennium. As these countries were among the first to have early access to the Internet outside the United States, the first international teleconsultation network had already established between the university hospitals of Tromsö (Norway), Oulu (Finland), and Reykjavik (Iceland) in 1993 (14). The Nordic countries were at the forefront of mobile communication networks and the first radiology consultation app for smartphones was taken into use in Oulu in 1999 (15).

At the start of the new millennium, the teleradiology articles in Acta concentrated on the new opportunities to modify radiology work practices. Meanwhile, the Internet revolution, standardization in medical informatics, especially the DICOM standard, and the EU's harmonization of professional regulations overcame many previous obstacles to large-scale teleradiology solutions. Eklöf et al. (16) evaluated the time required for transferring radiological information from Uppsala (Sweden) to Sydney (Australia). Image transmission over the Internet made it possible to provide consultations in night-time emergencies from another continent.

A recent article by Auer et al. (17) discussed process optimization within a nation-wide teleradiology consultation network. The authors showed that commercial-grade displays equaled medical-grade displays in diagnostic accuracy and readers' diagnostics in detecting and ruling out intracranial aneurysms. They concluded that this may have an economic and practical impact, reducing costs and increasing time efficacy, especially through more frequent availability of teleradiological services.

The teleradiology articles in Acta have followed the megatrends, but because the contents of Acta are mainly clinically oriented, the latest technology achievements in teleradiology seem to appear at a slight delay.

\section{Picture archiving and communication systems (PACS)}

Articles about picture archiving and communication systems (PACS) started to appear in radiologic journals in the late 1980s (18). The term PACS was first mentioned in Acta relatively early, perhaps due to the close relationship between the Scandinavian and Japanese radiology communities. A report from Hokkaido University Hospital described an experimental PACS, which was integrated with a hospital information system (19). Interestingly, as an alternative to the system-oriented PACS approach, a personal digital optical card (OC) was presented as a patient-oriented tool for the documentation and communication of images (20). The authors concluded 
that this low capacity write-once-read-many optical storage media may be a promising communication digital medium for transmitting an image/report unit to referring physicians. However, this OC did not achieve a widespread usage.

A worldwide standard for medical imaging, the ARC-NEMA-DICOM 3.0, was adopted in Europe during the mid-1990s and thus PACS was a major topic in 1996, when an editorial in Acta asked: "Are you considering replacing your old film archive with binary dots on magnetic and optical media, and replacing your reading sessions with a video monitor at almost every patient's bed?" (21). In the same issue, a baseline article described in detail the prerequisites for a filmless hospital and the various components needed for a PACS (22). At that time, economic calculations already showed that alternative technologies for digital image archives made full-scale PACS for filmless hospitals technologically and conceptually feasible, as well as financially mandatory.

The next article from 2001 about PACS in Acta discussed data migration, an inevitable result of rapidly evolving technology (23). The authors described the effort needed to migrate the contents of archives in a university hospital to a new environment. The data transfer proved to be labor-intensive, with high fault sensitivity in the storage media used. The costs of the work were considerable, and the authors emphasized the need for automated data migration. Since then, no major articles have been published on the general PACS concept in Acta. Only a short paper utilizing some tools from PACS workstations was published in 2012 (24). This is somewhat unexpected, given the fact that the Nordic countries have been pioneers in adapting the concept of filmless radiology.

\section{Radiology information systems (RIS)}

Computer systems have been in use for tasks commonly associated with RIS since the mid-1960s (25). Long before computers could be used to store electronic medical records, not to mention medical images, they were used for library rotation bookkeeping. The first report mentioning such a process was published in Acta in 1974 (26). Winter and Stein (26) described the conceptual framework of a computer-based library circulation system for the radiology file room. At that time, film jackets were frequently lost: "The most recent examinations are the most active, most frequently requested, and most difficult to find." They delineated a minimum set of information needed to manage film loans for the purpose of computer-based circulation and locator systems. At the beginning of the $1990 \mathrm{~s}$, personal computers (PC) were becoming cheaper and more common. As a result of this, the Finnish experience of the varying motivation levels of radiologists to file radiologic diagnoses on a PC was described in Acta (27). The same year, Ito (19) reported an advanced Japanese system from Hokkaido University
Hospital that incorporated computer-aided diagnosis (CAD). They had five years of experience of using a reporting system for CT and ultrasonography which utilized Bayes' theorem to calculate probable diseases. The calculations were based on the radiologists' classifications, which used subject coding consisting of anatomical, technical, and pathological conditions. Their system can be seen as a precursor to structured reporting, which has been further discussed in Acta by Indian researchers $(28,29)$ in their examples of reporting templates for the evaluation of the placenta, umbilical cord, and spinal dysraphism. A Taiwanese group introduced the idea of RIS worklist prioritization based on the findings of a CAD system in digital chest radiographs (30). They reported that CAD detection of abnormalities expediated the turnaround time for chest examinations by $44 \%$.

Concerns over data quality have been raised in Acta. Heikkinen et al. (31) reported on a study comparing CT reports from four teaching hospitals. Using a software tool, they evaluated 400 reports from 1995-1996 and compared them against the American College of Radiology (ACR) standard for written communication. They also investigated the structure and word count of the reports and recorded the number of diagnoses, differentials, and occurrences of demarcation definitions and size measures. They concluded that fewer than half of the reports followed the ACR standard and thus emphasized the need for standardizing the vocabulary. A Swedish study of crossorganizational workflow encountered similar problems (32). The researchers addressed the problem of missing or misused metadata and its adverse effects on regional workflow. They found, for example, that the DICOM tag "institutional department name" was frequently missing in the data and despite perhaps being self-evident in a single organization, this information is highly relevant when data are transferred between organizations. The authors argue that agreement on semantic operability is equally important for interoperability as decisions on technical details.

\section{Digital image}

At the beginning of the PACS era, concern was constantly voiced as to whether soft copy reading on monitors was sufficient for clinical practice. Digital images were printed on a film using medical laser printers and viewed on light boards. In 1990, studies of cheaper options, such as printing on paper with grayscale and color ink-jet printers $(33,34)$ or laser printers (35) were published in Acta, but gained no wider popularity. Concerns about the limitations of digital images were amplified when phosphor-based computed radiography (CR) systems and film scanners converted radiographs into digital form. High-resolution monitors were expensive and clinically acceptable resolutions and setups were discussed in Acta by a group from Lund and 
Gothenburg in three publications. Kehler et al. (36) found that viewing a $1760 \times 2140 \times 10$-bit digital chest image on a $1024 \times 1024$-pixel grayscale monitor was sufficient for routine diagnostic use in the evaluation of pulmonary and mediastinal nodules. Lyttkens et al. $(37,38)$ further studied whether the image quality of a PC with a $1200 \times$ $1024 \times 8$-bit grayscale monitor was sufficient for diagnostic needs in intensive care units when viewing digital chest radiographs. They found that viewing images displayed on a monitor and printed on a film were equally sufficient. Further, they compared RGB color and grayscale monitors of the same resolution and correspondingly found no significant difference between the performances of the setups.

In 1996, concerns about the storage capacity and network bandwidth inspired Icelandic researchers to study the lowest acceptable resolution of digital radiographs and the effect of compression algorithms on diagnostic quality in fracture detection (39). They concluded that a pixel size of $170 \mu \mathrm{m}$ was adequate for the detection of subtle fractures, even with a 10:1 compression ratio. Twelve years later, a Chinese group found a similar resolution to be sufficient for digitized mammograms viewed on a $1280 \times 1600$ matrix grayscale monitor (40). Savings in storage capacity motivated a group from Oslo to study the grayscale bit depth of MR images. They found that bit depth can be reduced from 12 to 8 bits with no significant reduction in diagnostic information (41). A further study in this domain was published by a group from China and Japan, which examined the effect of JPEG and the wavelet compression of CT images. They found that a compression ratio of up to $20: 1$ could be used without compromising the diagnostic value of high attenuation lesions such as coronary artery calcification (42).

After the turn of the millennium, display technology evolved from the cathode-ray tube (CRT) to a liquid-crystal display (LCD), and finally the quality of grayscale LCD monitors was estimated to also be sufficient for diagnostics from mammography readings (43). A study on chest radiographs revisited the quality of consumer-level displays with LCD-technology in 2015. Consumer-level technology was considered appealing because of its lower cost and versatility for also displaying color images (44). However, its performance was not yet regarded as sufficient for detecting part solid nodules. A year later, the same Japanese group concluded that a single $4096 \times 2160$ monitor was comparable to two $2048 \times 2560$ matrix monitors in reading time and the detectability of BI-RADS Category 3 or higher lesions (45).

\section{E-learning}

Currently, partly due to the COVID-19 pandemic, electronic learning is becoming one of the main education channels in healthcare. This topic was also studied in two articles published in Acta in the early 2000s. A Finnish group (46) studied the acceptance of an Internet-based learning environment for radiation protection training. The group concluded that medical doctors were very positive about Internet-based learning. Berry et al. (47) studied virtual reality simulation as a training method for carotid artery stenting. They quoted an old saying in procedural medicine, "first you get good and then you get fast," and discussed how fluoroscopic time may measure efficiency, but not necessarily quality. In their study, novices appeared to value simulator-based learning more than experts, but nonetheless, they suggested it be made mandatory in an endovascular curriculum.

\section{Image processing and visualization}

A hint of digital technology was found in Acta as early as in 1972 in a report describing ultrasound Midliner, an echo-encephalography device. Midliner was used to calculate distances from the scull to midline and it improved when a computer was used for the calculations. The improved device was found to be simpler and more objective than the conventional oscilloscope. The author suggested that this had the most value in peripheral hospitals in which inexperienced users operated such a device (48).

Postprocessing of images has been used in radiology in, for example, image enhancement or visualization. In 1991, a Japanese group studied how conventional tomographic images of the lung could be enhanced by image processing techniques based on unsharp mask filtering (49). However, this study has only historic value, as conventional focal plane tomography has now been replaced by $\mathrm{CT}$ and tomosynthesis.

Currently, postprocessing for 3D visualization is everyday practice and happens almost in real time. Several reports have been published in Acta on this domain. In 1996, a Japanese group studied a new three-dimensional method for analyzing the supratemporal plane using MRI and computer-aided graphics (50). A German group presented a pictorial essay and a postprocessing protocol of virtual cisternography based on 1.5-T MR images (51). In their study, postprocessing took 5-14 min per nerve. Ten years later, reconstruction time was reduced to $3-5 \mathrm{~min}$ in a virtual endoscopy application that was used to detect hypoplasia of the bony cochlear nerve canal (52). Virtual endoscopy postprocessing of the visualization of tracheobronchial abnormalities has also been reported in Acta and validated by comparing it to fiberoptic bronchoscopy $(53,54)$.

More recently, image-processing techniques have been utilized in preoperative planning. In 2016, a group from the Republic of Korea and China demonstrated patientspecific virtual stenting of intracranial aneurysms and an analysis of the subsequent changes in vascular flow (55). A recent review in 2020 by a US-based group discussed the potential applications of virtual and augmented reality 
in radiology. They suggested that studying 3D anatomy with head mounted displays could be an alternative to $3 \mathrm{D}$ printing, which has increasingly been used in procedural planning in particular. These methods could be used in education, training, and patient care, in which complex anatomy must be visualized. Current hardware and software can produce the required high-quality visualization in real time (56).

\section{Computer-aided diagnosis and artificial intelligence}

According to Doi et al. (57), systematic investigation of CAD began in the 1980s and the concept of "computeraided diagnosis" substituted the concept of "automated computer diagnosis." Earlier than that, some works published in Acta were a kind of precursor to the forthcoming era. In 1969, Park and O'Brien (58) analyzed the measurements obtained from the cervical films of patients with rheumatoid arthritis, using computer assistance in an attempt to predict the risk of sudden death. In 1970, Björk (59) used semi-automatic construction and computer analysis of curves in left ventricular cineangiography. These early papers used computers as a tool to help analyze the data obtained manually from film images. In 1982, a paper by Ruhn et al. (60) in Acta described an experimental model in which image data from simulated blood vessels was scanned into digital format and computerized quantitation of atherosclerosis was performed. The Hokkaido University Diagnostic Information Processing System (19) discussed earlier in this review also included CAD-like functionalities. Their system could produce probability scores for target diseases based on classified radiological findings.

The benefits of using CAD in diagnostics for radiologists were first published in Acta in the field of angiology. Sugahara et al. (61) noticed that radiologists detected stenotic coronary lesions more effectively with computer-aided interpretation than with pure visual interpretation. Another Japanese group (62) found similar results in experimental vessel stenosis. In their review article in 1993, Doi et al. (57) already summarized the potential application areas for CAD: "(1) the identification of lung nodules, the assessment of interstitial disease and cardiomegaly in chest radiographs; (2) the identification of clustered microcalcifications and masses in mammography; and (3) the assessment of stenotic lesions in angiograms."

Since the early 2000s, the focus of CAD publications in Acta have clearly shifted towards clinical feasibility. One of the main interest areas for CAD was the detection of breast cancer. In their paper, Kouskos et al. (63) presented that CAD performed statistically better in the classification of malignant and benign breast calcifications than physicians. Hukkinen and Pamilo (64) studied the performance of commercial CAD software in reading previous mammograms of surgically confirmed breast cancer cases. They noticed that
CAD had a rather high sensitivity but low specificity in cancer detection and concluded that it may be helpful for less specialized radiologists. Another article by the same institution (65) studied the effect of CAD on the mammographic performance of readers with different levels of experience. They found that screening radiologists benefitted slightly more from CAD than less experienced groups.

With the advent of full field digital mammography, more commercial CAD software appeared on the market, and the shortcomings of CAD technology, such as a high falsepositive rate in relation to its sensitivity became a research topic. In their article, Kim et al. (66) observed that falsepositive CAD marks were seen in approximately $70 \%$ of normal cases. They reminded readers that radiologists should be familiar with this issue in order to avoid an increased recall rate. In a follow-up article, they studied a new software version of the CAD system (67) and found that its sensitivity had improved, and the amount of falsepositive marks decreased. An acceptable false-positive rate was also found in a CAD study by Bolivar et al. (68). However, in another study of patients with contralateral metachronous breast cancer (69), CAD sensitivity was lower than in most previous reports.

It was not only mammography but also sonographic elastography modality that offered research topics for breast CAD. In their paper, Chung et al. (70) compared computer-assisted quantification and the visual assessment of lesion stiffness in the differentiation of benign from malignant nonpalpable breast masses and found their performance to be comparable. CAD tools were also studied in an analysis of dynamic breast MRI for the detection of suspicious enhancement curves (71) and in an analysis of the kinetic characteristics of the central washout sign of ductal carcinoma in situ (72).

The potential impact of CAD on double reading screening programs was evaluated in an early study by Skaane et al. (73). It concluded that CAD may have the potential to increase cancer detection and to reduce the number of interval cancers in screening programs. In their recent paper, Henriksen et al. (74) presented a systematic review of the efficacy of CAD in mammography screening. They found no statistically significant differences between the sensitivity or cancer detection rate of double reading and computer-assisted single reading. These articles imply that studies of mammography $\mathrm{CAD}$ have reached the level of discussing screening strategies.

Assessment of lung and chest examinations was another major territory for CAD studies. An article by Stavngaard et al. (75) in 2006 presented how computer-based quantification may offer new information on the distribution of emphysema and found significant discrepancies in comparison to subjective visual assessment. The reliability of computer-based quantification inspired a parallel editorial (76) which contradicted their conclusions. Interestingly, a more recent paper found that a postprocessing algorithm 
helped non-expert radiologists make appropriate diagnoses of usual interstitial pneumonia (UIP) in cases that could potentially be misdiagnosed as non-UIP (77).

As the follow-up of lung nodules has become a standard procedure, postprocessing software algorithms are being used to help the radiologist's work. In their study, Christe et al. (78) observed substantial inter- as well as intrasoftware variability. In their study of lung neoplasms with lepidic growth and computer-aided 3D volumetric CT analysis, Morimoto et al. (79) also showed that radiologists should know the capabilities and restrictions of their software algorithm tools.

An interesting paper examined the effect of CAD systems on the reporting workflow (30). In it, a CAD system automatically marked chest examinations with possible abnormalities in radiologists' work lists. The use of a CAD system reduced the turnaround time of chest examinations with abnormalities by $44 \%$, showing the potential of new IT solutions.

Reports on CAD in abdominal imaging or neuroimaging in Acta have been sparse. In their 2011 study, Kim et al. (80) found that a CAD system using the Bayesian classifier could improve the diagnostic performance of MR in detecting metastatic nodes in uterine cervical cancer. A more recent paper by Odland et al. (81) studied the semiautomatic segmentation and quantification of tumor growth in gliomas and found a tentative increase in segmentation efficiency, but with considerable inter-observer variability.

The term artificial intelligence (AI) was not mentioned in the article titles of Acta until 2020, when van Zelst et al. (82) published a concept study of the implementation of AI software with automated 3D breast ultrasound. They discussed modifications to screening workflow to potentially reduce workload by using CAD as a validator of screening radiologists' findings and adjusting the flow to double read based on validation results. Texture analysis, as a precursor to the current concept of radiomics, appeared for the first time as a title word in a paper by Kim and Park (83) on the computer-aided detection of kidney tumors in abdominal CT scans. Recently, Yang et al. (84) published a paper on texture analysis, which aimed to predict histological invasiveness within lung adenocarcinoma. Based on 96 automatically extracted texture features from segmented lung nodules, they found that the used method had the potential to differentiate histological invasiveness. Finally, a recent article by Losnegård et al. (85) on the usage of MR radiomics combined with machine learning for predicting extraprostatic extension (EPE) among patients with prostate cancer used radiomics as a title word. They concluded that MR radiomics may represent a valuable adjunct to conventional prediction models for EPE. This summarizes how intelligent tools for disease detection and diagnostics have migrated to the articles in Acta.

\section{Conclusion}

Digital technology is currently ubiquitous, and the emergence of innovations and methods can be seen in the pages of radiological journals, including Acta Radiologica. All our imaging methods are currently digitalized, some have been since their beginning and others have become so through evolution. The development of hardware has made fast data transfer and real-time data handling a common practice. Three-dimensional image processing is part of our everyday working lives and radiological data can be visualized in several different ways, sometimes merging modalities. Computers can manipulate an image with ease, but diagnostics is still almost always a human task. We are still waiting for $\mathrm{CAD}$ to become the everyday tool for a radiologist However, we are now witnessing the rapid progress of machine learning, and several AI techniques will affect our work in the future. This is reflected in the volume of different topics in this review. Most of the articles, especially the current ones, discuss how IT tools contribute to core radiology work. Radiologists have been eager to develop and evaluate technical innovations and have reported their observations in scientific journals to help others. This tradition does not necessarily secure that radiologists will also in the future hold the reins of powerful technologies like AI, but securing a leading role requires active participation from our profession in research and implementation.

\section{Declaration of conflicting interests}

The author(s) declared no potential conflicts of interest with GQ3 respect to the research, authorship, and/or publication of this article.

\section{Funding}

The author(s) received no financial support for the research, authorship, and/or publication of this article

\section{ORCID iDs}

Jarmo Reponen (iD https://orcid.org/0000-0003-2306-3111

Jaakko Niinimäki (iD https://orcid.org/0000-0002-5591-3726

\section{Supplemental material}

Supplemental material for this article is available online.

\section{References}

1. The Radio Doctor - Maybe! Radio News Magazine 1924, April.

2. Sending dental X-rays by telegraph. Dent Radiogr Photogr 1929;2:16-32.

3. Gershon-Cohen J, Cooley AG. Telognosis. Radiology 1950; 55: 582-587.

4. Jutras A. Teleroentgen diagnosis by means of video-tape recording. Am J Roentgenol Radium Ther Nucl Med 1959;82:1099-1102. 
5. Wallman H, Wickbom I. Roentgen-television equipment for use in surgery. Acta Radiol 1959;51:297-304.

6. Lindblom K. Roentgen television in surgery with special reference to stereo-television. Acta Radiol 1960;53:367-370.

7. Edholm P, Fernstrom I, Lindblom K, et al. Roentgen television in practice with special regard to puncture examinations. Acta Radiol Suppl 1962;216:1-80.

8. Arner O, Fernström I. Percutaneous splenic venography under roentgen television control. Acta Radiol Diagn (Stockh) 1964;2:53-58.

9. Holman CB. Evaluation of closed-circuit television technics in neuroroentgenology. Acta Radiol Diagn (Stockh) 1966;5:241-249.

10. Nilsson U, Nyman U, Nilsson M, et al. Teletransmission of radiographic images. Preliminary report. Acta Radiol Diagn (Stockh) 1986;27:357-360.

11. Korsoff L, Kallio T, Kormano M, et al. Experiences with a teleradiology system in pulmonary diseases. Acta Radiol 1995;36:37-40.

12. Størmer J, Bolle SR, Sund T, et al. ROC-study of a teleradiology workstation versus film readings. Acta Radiol 1997;38:176-180.

13. Kehler M, Bengtsson PO, Freitag M, et al. Teleradiology by two different concepts. Technical note. Acta Radiol 1997;38:338-339.

AQ5 14. Blinded for anonymity.

AQ6 15. Blinded for anonymity.

16. Eklöf H, Radecka E, Liss $P$, et al. Teleradiology Uppsala-Sydney for nighttime emergencies: preliminary experience. Acta Radiol 2007;48:851-853.

17. Auer TA, Münzfeld H, Posch H, et al. Evaluation of diagnostic accuracy of intracranial aneurysm detection using medicalgrade versus commercial consumer-grade displays and different image reconstructions against the background of process optimization for telemedicine. Acta Radiol 2020;61:936-944.

18. Huang HK, Mankovich NJ, Taira RK, et al. Picture archiving and communication systems (PACS) for radiological images: state of the art. Crit Rev Diagn Imaging 1988;28:383-427.

19. Ito S. A radiologic reporting system for computer-aided diagnosis with associated database. Hokkaido university diagnostic information processing system-HDIPS. Acta Radiol 1991;32:329-336.

20. Langer M, Buitrago-Téllez CH, Schulze C, et al. Digital optical card. A promising technology for documentation and communication of images. Acta Radiol 1995;36:674-678.

21. Jung B. Are you considering replacing you old film archive? Acta Radiol 1996;37:837.

22. Nissen-Meyer SA, Fink U, Pleier M, et al. The full-scale PACS archive. A prerequisite for the filmless hospital. Acta Radiol 1996;37:838-846.

23. Maass M, Kosonen M, Kormano M, et al. Radiological image data migration. Practical experience and comparison of the costs of work. Acta Radiol 2001;42:426-429.

24. Paik NC, Lim CS, Jang HS, et al. Numbering of vertebrae on MRI using a PACS cross-referencing tool. Acta Radiol 2012;53:785-789.

25. Nance JW, Meenan C, Nagy PG. The future of the radiology information system. Am J Roentgenol 2013;200:1064-1070.
26. Winter J, Stein MA, Conceptual framework of a computer based library circulation system for the radiology file room. Acta Radiol Diagn (Stockh) 1974;15:680-686.

27. Bondestam S. Personal computer in management of radiological data archive. Acta Radiol Suppl 1991;377:38-39.

28. Kumar I, Verma A, Jain M, et al. Structured evaluation and reporting in imaging of placenta and umbilical cord. Acta Radiol 2020;61:685-704.

29. Kumar I, Sachan A, Aggarwal P, et al. Structured MRI reporting in spinal dysraphism. Acta Radiol 2020;61:1520-1533.

30. Kao EF, Liu GC, Lee LY, et al. Computer-aided detection system for chest radiography: reducing report turnaround times of examinations with abnormalities. Acta Radiol 2015;56:696-701.

31. Heikkinen K, Löyttyniemi M, Kormano M, et al. Structure and content of $400 \mathrm{CT}$ reports in four teaching hospitals using a new, windows-based software tool. Acta Radiol 2000;41:102-105.

32. Lindsköld L, Wintell M, Edgren L, et al. Cross-organizational workflow in radiology: an empirical study of the quality of shared metadata elements in region Västra Götaland, Sweden. Acta Radiol 2013;54:676-683.

33. Johansson T, Nilsson J, Holmer NG, et al. Ink jet printing of digital radiographs. Acta Radiol 1990;31:108-110.

34. Nilsson J, Johansson T, Holmer NG, et al. Ink jet color printing of digital medical images. Acta Radiol 1990;31:414-416.

35. Liang Z, Du X, Guo X, et al. Comparison of dry laser printer versus paper printer in full-field digital mammography. Acta Radiol 2010;51:235-239.

36. Kehler M, Albrechtsson U, Arnadóttir E, et al. Digital luminescence radiography using a chest phantom. Comparison between radiographs displayed on monitor and hard-copy. Acta Radiol 1992;33:117-122.

37. Lyttkens K, Andersson B, Kehler M, et al. Bedside chest radiography using digital luminescence. A comparison between digital radiographs reviewed on a personal computer and as hard-copies. Acta Radiol 1992;33:427-430.

38. Lyttkens K, Kehler M, Andersson B, et al. Digital luminescence radiography using a chest phantom. Comparison between radiographs displayed on monitor at a workstation and at a personal. Acta Radiol 1993;34:440-444.

39. Jónsson A, Laurin S, Karner G, et al. Spatial resolution requirements in digital radiography of scaphoid fractures. An ROC analysis. Acta Radiol 1996;37:555-560.

40. Liang Z, Du X, Liu J, et al. Comparison of diagnostic accuracy of breast masses using digitized images versus screen-film mammography. Acta Radiol 2008;49:618-622.

41. Smith HJ, Bakke SJ, Smevik B, et al. Comparison of 12-bit and 8-bit gray scale resolution in MR imaging of the CNS. An ROC analysis. Acta Radiol 1992;33:505-511.

42. Zheng LM, Sone S, Itani Y, et al. Effect of CT digital image compression on detection of coronary artery calcification. Acta Radiol 2000;41:116-121.

43. Cha JH, Moon WK, Cho N, et al. LCD Versus CRT monitors for digital mammography: a comparison of observer performance for the detection of clustered microcalcifications and masses. Acta Radiol 2009;50:1104-1108.

44. Yabuuchi H, Matsuo Y, Kamitani T, et al. Detectability of T1a lung cancer on digital chest radiographs: an observerperformance comparison among 2-megapixel general- 
purpose, 2-megapixel medical-purpose, and 3-megapixel medical-purpose liquid-crystal display (LCD) monitors. Acta Radiol 2015;56:943-949.

45. Jinnouchi M, Yabuuchi H, Kubo M, et al. Utility of adaptive control processing for the interpretation of digital mammograms. Acta Radiol 2016;57:1297-1303.

46. Autti T, Autti H, Vehmas T, et al. E-learning is a wellaccepted tool in supplementary training among medical doctors: an experience of obligatory radiation protection training in healthcare. Acta Radiol 2007;48:508-513.

47. Berry M, Reznick R, Lystig T, et al. The use of virtual reality for training in carotid artery stenting: a construct validation study. Acta Radiol 2008;49:801-805.

48. Gordon D. Objective echo-encephalography using a computer technique. Acta Radiol Diagn (Stockh) 1972;13:709-714.

49. Sone S, Kasuga T, Sakai F, et al. Digital image processing to remove blur from linear tomography of the lung. Acta Radiol 1991;32:421-425.

50. Utsunomiya H, Nawata M, Ogasawara T, et al. Size and asymmetry of the planum temporale. A new three- dimensional method for analysis of the supratemporal plane using MR imaging and computer-aided graphics. Acta Radiol 1996;37:57-62.

51. Heine C, Klingebiel R, Lehmann R, et al. Three-dimensional MR visualization of the intracisternal course of the cranial nerves V-VIII by virtual cisternoscopy. Acta Radiol 2002;43:242-248.

52. Quan Y, Liu J, Liu Z, et al. Detection of hypoplasia of bony cochlear nerve canal by the opening threshold of virtual endoscopy: a pilot study. Acta Radiol 2014;55:318-324.

53. Maniatis PN, Triantopoulou CC, Tsalafoutas IA, et al. Virtual bronchoscopy versus thin section computed tomography in evaluation of moderate and low grade stenoses: receiver operating characteristic curve analysis. Acta Radiol 2006;47:4857.

54. Akhlaghpoor S, Ahari AA, Shabestari AA, et al. Comparison of virtual bronchoscopy with fiberoptic bronchoscopy findings in patients exposed to sulfur mustard gas. Acta Radiol 2011;52:1095-1100.

55. Song Y, Choe J, Liu H, et al. Virtual stenting of intracranial aneurysms: application of hemodynamic modification analysis. Acta Radiol 2016;57:992-997.

56. Elsayed M, Kadom N, Ghobadi C, et al. Virtual and augmented reality: potential applications in radiology. Acta Radiol 2020;61:1258-1265.

57. Doi K, Giger ML, Nishikawa RM, et al. Digital radiography. A useful clinical tool for computer-aided diagnosis by quantitative analysis of radiographic images. Acta Radiol 1993;34:426-439.

58. Park WM, O'Brien W. Computer-assisted analysis of radiographic neck lesions in chronic rheumatoid arthritis. Acta Radiol Diagn (Stockh) 1969;8:529-534.

59. Björk L. Semi-automatic construction and computer analysis of volume curves and pressure-volume curves in left ventricular cineangiography. Acta Radiol Diagn (Stockh) 1970;10:413-426.

60. Ruhn G, Erikson U, Helmius G, et al. Computerized quantitation of atherosclerosis in an experimental model. Arteriography and microdensitometry. Acta Radiol Diagn (Stockh) 1982;23:621-624.
61. Sugahara T, Yamagihara Y, Sugimoto N, et al. Computer-aided interpretation of coronary cineangiograms. Accuracy of automatic detection of stenotic lesions. Acta Radiol 1992;33:6-9.

62. Yanagihara Y, Sugahara T, Fukunishi Y, et al. Visual interpretation compared with caliper and computerized measurements in experimental vessel stenosis. Acta Radiol 1992;33:542-545.

63. Kouskos E, Markopoulos C, Revenas K, et al. Computer-aided preoperative diagnosis of microcalcifications on mammograms. Acta Radiol 2003;44:43-46.

64. Hukkinen K, Pamilo M, Does computer-aided detection assist in the early detection of breast cancer? Acta Radiol 2005;46:135-139.

65. Hukkinen K, Vehmas T, Pamilo M, et al. Effect of computeraided detection on mammographic performance: experimental study on readers with different levels of experience. Acta Radiol 2006;47:257-263.

66. Kim SJ, Moon WK, Seong MH, et al. Computer-aided detection in digital mammography: false-positive marks and their reproducibility in negative mammograms. Acta Radiol 2009;50:999-1004.

67. Kim SJ, Moon WK, Kim SY, et al. Comparison of two software versions of a commercially available computer-aided detection (CAD) system for detecting breast cancer. Acta Radiol 2010;51:482-490.

68. Bolivar AV, Gomez SS, Merino P, et al. Computer-aided detection system applied to full-field digital mammograms. Acta Radiol 2010;51:1086-1092.

69. Kim SJ, Moon WK, Cho N, et al. Computer-aided detection system performance on current and previous digital mammograms in patients with contralateral metachronous breast cancer. Acta Radiol 2012;53:376-381.

70. Chung SY, Moon WK, Choi JW, et al. Differentiation of benign from malignant nonpalpable breast masses: a comparison of computer-assisted quantification and visual assessment of lesion stiffness with the use of sonographic elastography. Acta Radiol 2010;51:9-14.

71. Vag T, Baltzer PA, Dietzel M, et al. Kinetic characteristics of ductal carcinoma in situ (DCIS) in dynamic breast MRI using computer-assisted analysis. Acta Radiol 2010;51:955-961.

72. Ko ES, Choi HY, Lee BH, et al. Central washout sign in computer-aided evaluation of breast MRI: preliminary results. Acta Radiol 2011;52:256-263.

73. Skaane P, Kshirsagar A, Hofvind S, et al. Mammography screening using independent double reading with consensus: is there a potential benefit for computer-aided detection? Acta Radiol 2012;53:241-248.

74. Henriksen EL, Carlsen JF, Vejborg IM, et al. The efficacy of using computer-aided detection (CAD) for detection of breast cancer in mammography screening: a systematic review. Acta Radiol 2019;60:13-18.

75. Stavngaard T, Shaker SB, Bach KS, et al. Quantitative assessment of regional emphysema distribution in patients with chronic obstructive pulmonary disease (COPD). Acta Radiol 2006;47:914-921.

76. Tylén U. Computerized diagnosis of emphysema. Acta Radiol 2006;47:886-887.

77. Fujita R, Iwasawa T, Aoki T, et al. Detection of the usual interstitial pneumonia pattern in chest $\mathrm{CT}$ : effect of computer- 
aided diagnosis on radiologist diagnostic performance. Acta Radiol. DOI: 10.1177/0284185120902393 [Epub ahead of AQ7 print].

AQ8 78. Christe A, Brönnimann A, Vock P, et al. Volumetric analysis of lung nodules in computed tomography (CT): comparison of two different segmentation algorithm softwares and two different reconstruction filters on automated volume calculation. Acta Radiol 2014;55:54-61.

79. Morimoto D, Takashima S, Sakashita N, et al. Differentiation of lung neoplasms with lepidic growth and good prognosis from those with poor prognosis using computer-aided 3D volumetric CT analysis and FDG- PET. Acta Radiol 2014;55:563-569.

80. Kim MH, Kim JK, Lee Y, et al. Diagnosis of lymph node metastasis in uterine cervical cancer: usefulness of computeraided diagnosis with comprehensive evaluation of MR images and clinical findings. Acta Radiol 2011;52:1175-1183.

81. Odland A, Server A, Saxhaug C, et al. Volumetric glioma quantification: comparison of manual and semi- automatic tumor segmentation for the quantification of tumor growth. Acta Radiol 2015;56:1396-1403.

82. van Zelst JC, Tan T, Mann RM, et al. Validation of radiologists' findings by computer-aided detection (CAD) software in breast cancer detection with automated 3D breast ultrasound: a concept study in implementation of artificial intelligence software. Acta Radiol 2020;61: 312-320.

83. Kim DY, Park JW, Computer-aided detection of kidney tumor on abdominal computed tomography scans. Acta Radiol 2004;45:791-795.

84. Yang Y, Wang WW, Ren Y, et al. Computerized texture analysis predicts histological invasiveness within lung adenocarcinoma manifesting as pure ground-glass nodules. Acta Radiol 2019;60:1258-1264.

85. Losnegård A, Reisæter LAR, Halvorsen OJ, et al. Magnetic resonance radiomics for prediction of extraprostatic extension in non-favorable intermediate- and high-risk prostate cancer patients. Acta Radiol 2020;61:1570-1579. 